HS 1 | 2011

Mettre en scène l'événement

\title{
Préempter tout commentaire et tout jugement
}

Extrait d'un entretien réalisé le 19 juillet 2011

Michel Vinaver et Jean-Loup Rivière

\section{CpenEdition}

Journals

Édition électronique

URL : https://journals.openedition.org/agon/1804

DOI : 10.4000 /agon. 1804

ISSN : 1961-8581

Éditeur

Association Agôn

Référence électronique

Michel Vinaver et Jean-Loup Rivière, « Préempter tout commentaire et tout jugement », Agôn [En ligne], HS 1 | 2011, mis en ligne le 02 septembre 2011, consulté le 08 décembre 2022. URL : http:// journals.openedition.org/agon/1804; DOI : https://doi.org/10.4000/agon.1804 

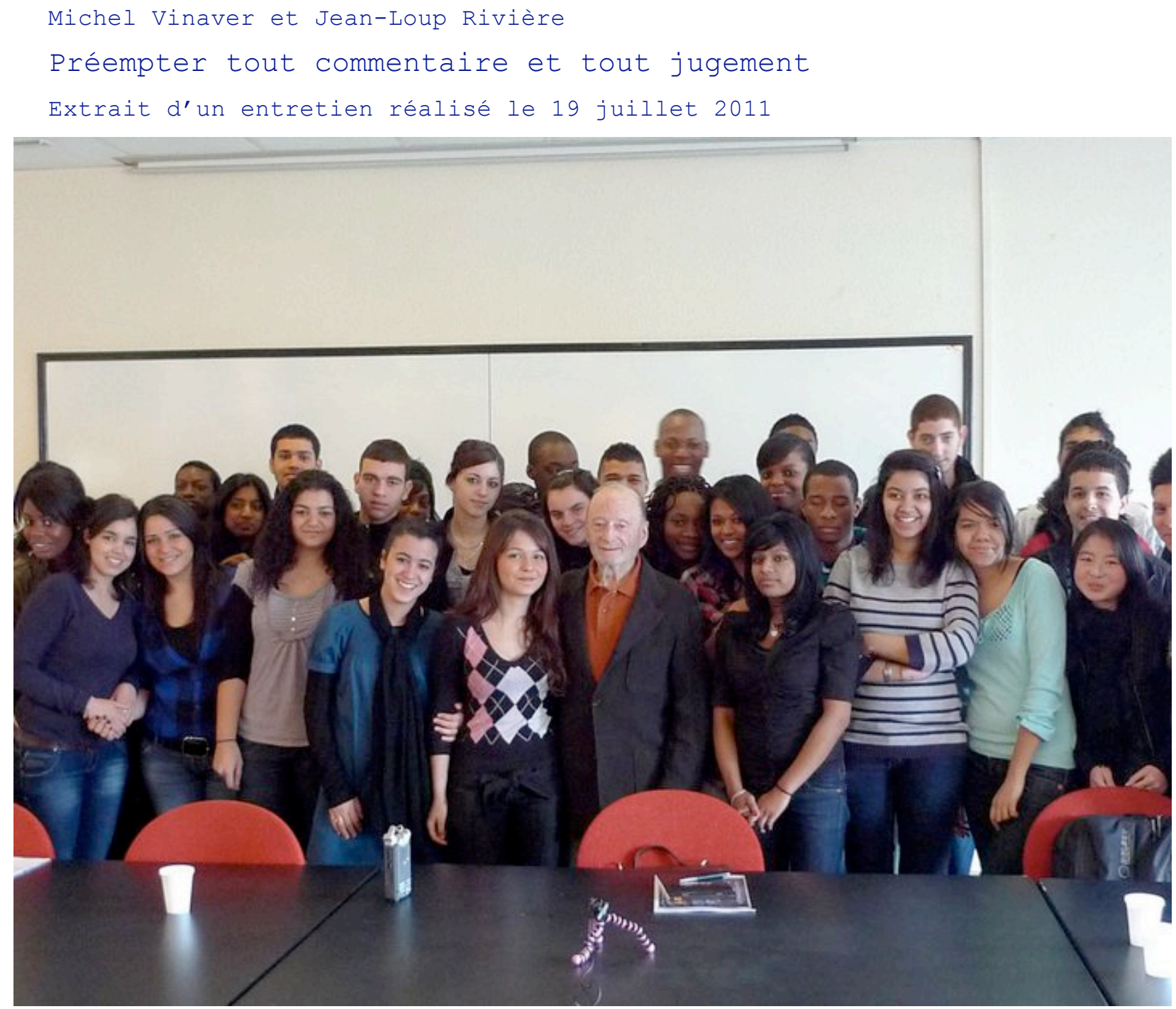

Michel Vinaver avec les élèves de la classe de 1STG2 du lycée Voillaume (C) Marie-Laure Basuyaux

Jean-Loup Rivière - Concrètement, combien de temps après l'événement avez-vous décidé d'écrire la pièce ?

Michel Vinaver - Je pense que c'était de l'ordre de deux ou trois semaines.

J.-L. R. - Et le temps d'écriture de la pièce a été très rapide ?

M. V. - Oui. Très rapide.

J.-L. R. - Avec beaucoup de documentation?

M. V. - La documentation, c'était les coupures de journaux, essentiellement le Herald Tribune. Rien n'existait alors qui aurait été de l'ordre d'un commentaire, ou bien les commentaires étaient encore tout à fait journalistiques et ne m'intéressaient pas tellement. Ce que j'ai voulu avec cette pièce, c'est préempter les commentaires. Je voulais préempter tout commentaire et tout jugement. J.-L. R. - Pourquoi n'avez-vous pas écrit de pièce sur la chute du mur de Berlin, qui est l'autre grand événement de ces dernières décennies ?

M. V. - Je peux l'expliquer en continuant sur le 11 septembre: l'événement était déjà immédiatement mythique, par le fait que tout le monde l'avait vu. Il y avait un effet de saturation, de stupéfaction, de sidération, toutes sortes de sentiments mélangés. Je me suis dit : « Il faut faire vite avant que ne se sédimente une sorte de mémoire collective, une forme de vulgate dans le 
choix des images et des propos. » Je voulais partir d'un pêle-mêle, d'un chaos. Et ce chaos, dans mon esprit peut-être naïf, c'était une façon de reproduire l'événement lui-même, c'est-à-dire les décombres, les choses qui volent en éclats, les décombres - ces amas non hiérarchisés. Pour moi, le mur de Berlin a été une immense surprise, mais plus distante. Je n'ai pas eu le même accès à l'immédiateté de l'événement.

J.-L. R. - [...] Quand vous employez l'expression « reproduire l'événement », c'est une chose nouvelle, non ? Il me semble que cet accent porté sur la reproduction est une chose nouvelle.

M. V. - Ce que j'avais dans l'esprit pendant que je le faisais, c'est les grottes de Chauvet, Cosqueret et Lascaux : pourquoi les animaux qui courraient autour des gens se sont retrouvés être reproduits ? Au-delà de toutes les explications, vaseuses d'ailleurs, sur le sacré, les rites, etc, dont on ne saura jamais rien, le fait est que c'était des reproductions à l'identique. Mais des reproductions à l'identiques sont néanmoins totalement distinctes de l'objet lui-même, de l'objet reproduit. J'avais conscience d'être dans ce type de paradoxe : je reproduisais l'événement, mais l'événement resterait totalement autre. On touche là à une grande question sans réponse: pourquoi l'art ? Pourquoi imiter? [...]

Ce qui est propre à 11 septembre du point de vue de cette proximité ou pas, c'est ce qui fait que les lycéens qui travaillent le texte en ce moment n'ont pas de problème avec la pièce, c'est que la langue n'est pas retravaillée dans sa micro composition. La composition est dans la structure, mais si on prend une réplique quelconque, elle est très proche - qu'elle soit brute, reproduite verbatim ou qu'elle ait été inventée - de ce que serait le discours journalier dans une situation intime. Je prends, par exemple, le début de la dernière réplique de la pièce, qui ne fait pas partie du montage, mais est inventée :

Bien sûr oui bien sûr il aurait fallu que j'y sois au bureau.

Dieu merci Tony a eu son indigestion il a vomi toute la nuit ${ }^{1}$

Les jeunes qui débarquent dans ce texte, ils y entrent; ils n'ont pas l'impression d'entrer dans quelque chose qui leur demande un apprentissage. C'est un des facteurs de leur plaisir. Si la plupart d'entre eux sont restés dans le projet d'Arnaud Meunier, c'est qu'ils y trouvaient leur compte de ce point de vue-là : comment on parle.

Un article rendant compte de l'intégralité de cet entretien sera mis en ligne dans les jours qui viennent, ainsi que des extraits d'une conversation entre Michel Vinaver et le sociologue Luc Boltanski, Le capitalisme et la représentation (12 juillet 2011).

Pour citer ce document

Michel Vinaver et Jean-Loup Rivière, «Préempter tout commentaire et tout jugement», Agôn [En ligne], Dossiers, HS n ${ }^{\circ} 1$ : Mettre en scène l'événement, 11 septembre 2001 de Michel Vinaver, mis à jour le : 05/09/2011, URL : http://agon.ens-lyon.fr/index.php?id=1804.

\footnotetext{
${ }^{1}$ Michel Vinaver, 11 septembre 2001, Théâtre complet 8, L'Arche, Paris, 2003, p. 181.
} 